\title{
ANALISIS TREN PENCARIAN INFORMASI: KASUS KEDAI KOPI RAMU
}

\author{
ANALYSIS OF INFORMATION SEEKING TRENDS: \\ THE CASE OF RAMU COFEE SHOP
}

\author{
Linda Ramadhanti*, Sri Fatimah \\ Program Studi Agribisnis, Fakultas Pertanian, Universitas Padjadjaran \\ *E-mail: linda17004@mail.unpad.ac.id \\ (Diterima 09-04-2021; Disetujui 03-06-2021)
}

\begin{abstract}
ABSTRAK
Kedai Kopi Ramu diduga mengalami pergeseran fungsi, sekarang kedai kopi menjadi ajang sosialisasi dan media pencarian informasi. Penjualan Kedai Kopi Ramu masih berfluktuasi bahkan cenderung menurun padahal konsumsi kopi di Indonesia dalam lima tahun terakhir terus meningkat. Dalam rangka meningkatkan penjualannya, Kopi Ramu beriklan di media sosial instagram menggunakan fitur Instagram Ads, namun belum diketahui sejauh mana efektivitasnya. Penelitian bertujuan untuk mendeskripsikan karakteristik dan perilaku pencarian informasi followers instagram Kopi Ramu, serta efektivitas iklan produk Kopi Ramu pada media sosial instagram. Metode penelitian yang digunakan adalah analisis deskriptif dan skor rata-rata. Hasil penelitian menunjukkan bahwa followers instagram Kopi Ramu didominasi oleh pelajar/mahasiswa berusia 20-25 tahun, tidak terbatas pada jenis kelamin tertentu, serta berpendidikan terakhir berupa lulusan SMA atau sederajat dengan pendapatan di bawah Rp 1.000.000. Iklan Kopi Ramu yang ditampilkan pada media sosial instagram berada pada kategori "Efektif" dengan hasil skor rata-rata sebesar 4,05. Perilaku pencarian informasi di Kedai Kopi Ramu adalah "Positif" dengan hasil skor rata-rata sebesar 3,697.
\end{abstract}

Kata kunci: Iklan, Model AISAS, Perilaku Pencarian Informasi, Kopi Ramu

\section{ABSTRACT}

The Ramu Coffee Shop is thought to have experienced a shift in function, now the coffee shop has become a place for socialization and information-seeking media. The sales of Ramu Coffee Shops are still fluctuating and even tend to decline, even though coffee consumption in Indonesia has continued to increase in the last five years. In order to increase sales, Kopi Ramu advertises on Instagram social media using the Instagram Ads feature, but it is not yet known to what extent its effectiveness. The study aims to describe the characteristics and information-seeking behavior of Kopi Ramu's followers, as well as the effectiveness of Kopi Ramu product advertisements on Instagram social media. The research method used is descriptive analysis and average score. The results showed that the followers of Kopi Ramu Instagram were dominated by students aged 20-25 years, not limited to a certain gender, and the latest education was a high school graduate or equivalent with an income of less than Rp. 1,000,000. Kopi Ramu advertisements displayed on instagram social media are in the "Effective" category with an average score of 4.05. Information seeking behavior at the Ramu Coffee Shop is "Positive" with an average score of 3.697.

Keywords: Advertisement, AISAS Model, Information Seeking behavior, Kopi Ramu

\section{PENDAHULUAN}

Perkembangan teknologi modern

telah memberikan dampak kehidupan yang menjadi lebih cepat, praktis, dan ekonomis. Kemudian menyebabkan industri modern juga berkembang sangat 
cepat. Industri kafe merupakan salah satu industri yang perkembangannya pesat dengan peminatnya yang banyak. Industri kafe merupakan salah satu industri yang perkembangannya pesat dengan peminatnya yang banyak. Banyaknya jenis kafe di Indonesia, Kedai Kopi (coffee shop) merupakan usaha yang sedang menjamur di Indonesia. Dulu kopi identik dengan minuman untuk para orang tua, kopi kini menjadi tren baru anak muda. Generasi anak muda masa kini yang disebut dengan generasi milenial sudah tidak canggung lagi dengan istilah-istilah sajian kopi yang diadaptasi dari negara barat, seperti, cappuccino, espresso, ataupun latte (Prakosa, 2019). Globalisasi telah mempengaruhi kebiasaan minum kopi, para peminum kopi yang biasa minum kopi di warung pinggir jalan hingga menjadi ke kedai kopi. Minum kopi sudah menjadi kebiasaan dan kegiatan sehari-hari masyarakat terutama yang tinggal di daerah perkotaan. Minum kopi bagi masyarakat kota sudah menjadi life style dimana berbagai kedai kopi di perkotaan tidak pernah sepi pengunjung meskipun harga secangkir kopi di kedai kopi cukup mahal. Gaya hidup kebanyakan remaja cenderung berorientasi pada nilai material dan prestise. Kesan modernitas dan prestise cenderung banyak diminati oleh generasi milenial (Fauzi, 2020). Berdasarkan hasil penelitian Solikatun et al (2015), perilaku mengonsumsi kopi dilakukan untuk mengikuti gaya hidup masyarakat modern yang eksklusif dan mengutamakan prestise, meskipun peminum kopi mengetahui bahwa apa yang dikonsumsi terkadang tidak sesuai dengan apa yang diinginkan. Hasil penelitian Nurikhsan et al (2019) menunjukkan bahwa ada berbagai motivasi yang melatarbelakangi generasi milenial lebih memilih untuk menikmati secangkir kopi di kedai kopi. Selain untuk bercengkrama dengan temanteman, dengan adanya fasilitas wifi membuat kedai kopi digemari kaum milenial yang ingin mendapatkan internet gratis. Suasana serta konsep dari kedai kopi yang menarik juga menjadi faktor mengapa kedai kopi banyak didatangi oleh para remaja. Remaja tidak lagi berkunjung ke kedai kopi hanya untuk secangkir kopi tetapi untuk menaikkan gengsi mereka. Berdasarkan data International Coffee Organization (ICO), konsumsi kopi dunia dalam lima tahun terakhir terus meningkat. 


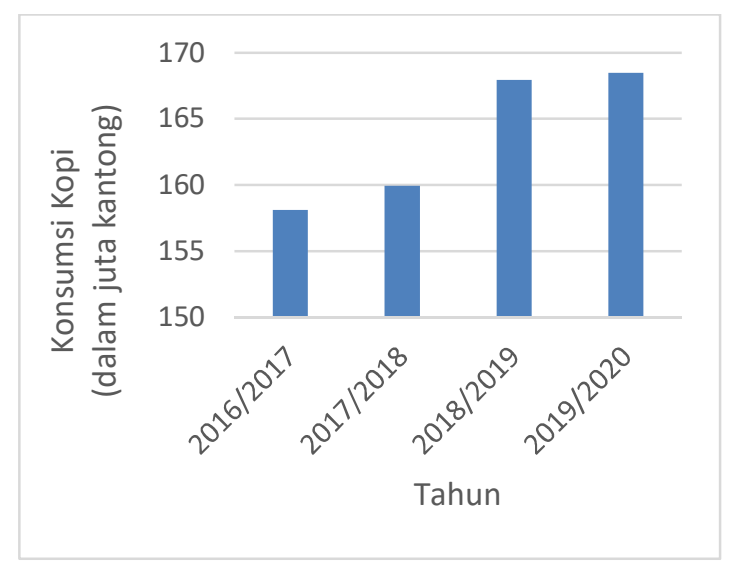

Gambar 1. Konsumsi Kopi Dunia (ICO, 2020)

Berdasarkan grafik di atas, konsumsi kopi pada periode 2019-2020 mencapai 168,492 juta kantong (ukuran 60 kilogram). Jumlah tersebut meningkat 6,73 persen dibandingkan dengan tahun 2016-2017 yang mencapai 158,124 juta kantong. Indonesia sebagai negara pengekspor kopi juga terus mengalami peningkatan dalam lima tahun terakhir. Konsumsi kopi pada periode 2019-2020 mencapai 4,8 juta kantong. Jumlah tersebut meningkat 3,125 persen dibandingkan dengan tahun 2016-2017 yang mencapai 4,65 juta kantong. Peningkatan konsumsi kopi ini dipicu oleh maraknya kopi kekinian, yakni es kopi yang dicampur dengan susu segar dengan tambahan rasa gula aren, sirup vanilla, pandan, dan variasi lain. Peningkatan konsumsi kopi di Indonesia ternyata tidak berbanding lurus terhadap penjualan di Kedai Kopi Ramu. Berikut merupakan data penjualan Kopi Ramu:

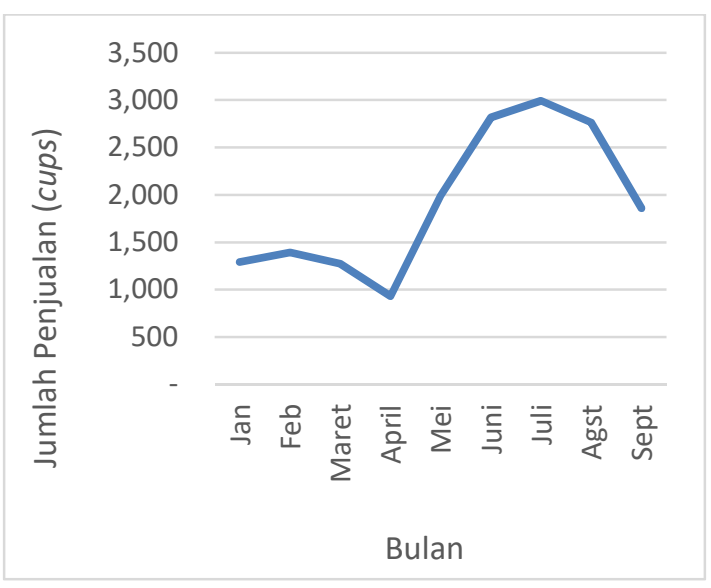

Gambar 2. Data Penjualan Kopi Ramu (Kopi Ramu, 2020)

Berdasarkan grafik di atas, penjualan Kopi Ramu mengalami fluktuasi bahkan cenderung menurun. Penjualan Kopi Ramu pada bulan Februari mencapai 1.394 cup. Jumlah tersebut meningkat 7,24 persen dibandingkan dengan bulan Januari yang mencapai 1.293 cup, namun pada bulan Maret penjualan Kopi Ramu menurun 9,5 persen. Pada bulan April, Kopi Ramu hanya berhasil menjual 930 cup. Jumlah tersebut menurun 49,9 persen dibandingkan dengan bulan Februari. Tiga bulan setelah itu, Kopi Ramu terus mengalami peningkatan penjualan yang cukup signifikan, namun penjualan mulai kembali menurun pada bulan Agustus. Pada bulan September, Kopi Ramu mengalami penurunan 48,5 persen dibandingkan dengan bulan Agustus. Kopi Ramu berupaya mengembangkan cara-cara kreatif supaya dapat meningkat penjualan Kopi Ramu. Salah satunya 
dengan memasarkan produk kopi secara online dengan gencar supaya dapat menjangkau pasar lebih luas. Salah satu media sosial yang populer di masyarakat Indonesia terutama kaum milenial adalah instagram. Instagram menduduki posisi ke 3 dalam platform media sosial yang paling banyak digunakan, dan 85 juta orang di Indonesia dapat dijangkau melalui instagram. Instagram memiliki 58 kali lebih banyak engagement per pengikut dibandingkan Facebook. Kelompok usia paling aktif di instagram adalah umur 18-34 tahun. Kedai Kopi kini banyak diminati oleh kaum milenial, maka dari itu sangatlah efektif jika melakukan promosi di instagram yang penggunanya didominasi oleh kaum milenial.

Para pelaku usaha tertarik dengan instagram ads karena melihat perkembangan pengguna instagram yang semakin meningkat. Berdasarkan penelitian Bestriandita dan Widodo (2017), iklan melalui media sosial instagram lebih efektif dibandingkan media sosial lainnya. Instagram memperoleh skor EPIC paling besar yaitu 3,471 yang berada dalam rentang skala efektif. Youtube berada di urutan kedua dengan skor EPIC sebesar 3,24 yang dalam rentang skala cukup efektif.
Sedangkan Facebook dan Twitter berada dalam rentang skala tidak efektif.

Dalam rangka meningkatkan penjualannya, Kopi Ramu beriklan di media sosial instagram menggunakan fitur Instagram Ads. Kopi Ramu berupaya untuk memberikan konten menarik yang dapat menimbulkan minat beli konsumen dengan cara menampilkan iklan-iklan mengenai produk Kopi Ramu. Berdasarkan hasil penelitian Echsanullah dan Wulandari (2018), iklan media online mempunyai pengaruh terhadap penjualan dengan arah positif sebesar 194,449, artinya semakin tinggi biaya iklan semakin tinggi pula penjualan yang dihasilkan. Penelitian Kopi Ramu harus memperhatikan kegunaan media sosial yang sesuai dengan target pasarnya agar pesan yang diberikan dapat diterima oleh konsumen. Hal tersebut akan menimbulkan keputusan pembelian pada pelanggan untuk membeli produk yang dipromosikan. Maka dari itu, iklan produk Kopi Ramu melalui media sosial instagram harus efektif.

Penelitian ini menggunakan model AISAS (Attention, Interest, Search, Action, Share) untuk mengukur efektivitas iklan produk Kopi Ramu pada media sosial instagram. Konsep AISAS didapat dari perkembangan teknologi 
yang sudah mengarah kepada era internet yang memunculkan dua perilaku unik konsumen yaitu searching dan sharing information yang diberi nama dengan model AISAS (Sugiyama dan Andree, 2011). Berdasarkan hal tersebut, pengukuran efektivitas iklan dalam penelitian ini menggunakan model AISAS karena yang diteliti adalah iklan pada media sosial instagram.

Selain beriklan di media sosial instagram, Kopi Ramu perlu memahami kebutuhan dan keinginan konsumen untuk meningkatkan penjualannya. Kopi Ramu diduga mengalami pergeseran fungsi. Dulu konsumen ke kedai kopi hanya untuk minum kopi semata. Sekarang kedai kopi menjadi tempat mencari informasi penting, diskusi, bersosialiasi, serta mencari hiburan. Berdasarkan hasil penelitian Fauzi (2020), café atau kedai kopi merupakan sebuah wadah yang memberikan tempat bagi masyarakat terutama generasi milenial Pengalengan untuk melakukan interaksi masyarakat Kecamatan Pengalengan. Banyak yang mengaku bahwa café dan kedai kopi dapat memberikan informasi dan inspirasi. Hasil penelitian Firsyawardana dan Rahmanto (2019) juga menunjukkan bahwa adanya motif pencarian informasi dalam mengunjungi kedai kopi. Saat berkunjung Kedai Kopi Bertopi, informan ingin mendapatkan pengetahuan tentang bagaimana sajian kopi yang ditawarkan oleh kedai kopi ini. Selain itu, informan juga memanfaatkan kehadiran orang yang dikenal untuk memberikan informasi mengenai komposisi dari sajian-sajian kopi yang dihadirkan di Kedai Kopi Bertopi. Adanya motif pencarian informasi dalam mengunjungi kedai kopi dapat menjadi pertimbangan Kopi Ramu dalam beriklan. Pencarian informasi adalah tujuan beralasan untuk menemukan informasi sebagai konsekuensi untuk memuaskan suatu tujuan. Sedangkan definisi Brenda Dervin dari sense-making dalam menghadapi situasi problematis. Dalam menghadapi situasi problematis, seseorang kini tidak hanya diam di rumah saja melainkan mencari tempat untuk berdiskusi menyelesaikan masalah. Café menjadi salah satu tujuan seseorang untuk mencari informasi dalam kasus ini merupakan Kedai Kopi Ramu. Penelitian ini bertujuan untuk mengetahui karakteristik followers instagram Kopi Ramu, mengukur tingkat efektivitas iklan produk Kopi Ramu pada media sosial instagram berdasarkan model AISAS, serta mengetahui perilaku pencarian 
informasi sebagai gaya hidup konsumen Kopi Ramu.

\section{METODE PENELITIAN}

Penelitian ini dilakukan di Kopi Ramu yang berlokasi di Jalan Melati Raya No. 129A, RT.08/RW.05, Kelurahan Depok Jaya, Kecamatan Pancoran Mas, Kota Depok, Jawa Barat. Pemilihan Ramu sebagai lokasi penelitian dilakukan secara sengaja karena Kopi Ramu merupakan kedai kopi yang penjualannya masih berfluktuasi saat konsumsi kopi di Indonesia terus meningkat dan sedang gencar melakukan promosi di instagram untuk dapat merebut hati konsumen.

Penelitian ini menggunakan desain penelitian kuantitatif. Desain penelitian kuantitatif dilakukan untuk menguji teoriteori tertentu dengan cara meneliti hubungan antar variabel. Variabelvariabel biasanya diukur dengan instrumen-intrumen penelitian sehingga data yang terdiri atas angka-angka dapat dianalisis berdasarkan prosedur-prosedur statistik (Cresswell, 2016). Metode yang digunakan oleh peneliti adalah metode penelitian survei dengan analisis deskriptif.

Jenis data yang digunakan dalam penelitian ini adalah data kuantitatif sebagai fokus utama dan data kualitatif sebagai data pendukung. Data kuantitatif diperoleh melalui kuesioner online yang diberikan kepada responden. Sedangkan data kualitatif diperoleh dengan melakukan wawancara singkat dengan responden serta wawancara kepada pihak Kopi Ramu. Teknik pengambilan sampel dalam penelitian ini menggunakan nonprobability sampling dengan teknik accidental sampling. Instrumen yang digunakan dalam penelitian ini adalah kuesioner yang menggunakan skala pengukuran likert. Kuesioner disebarkan kepada 100 responden yang merupakan followers (pengikut) akun instagram Kopi Ramu dan pernah berinteraksi dengan akun instagram Kopi Ramu seperti memberikan komentar atau pernah memberi tanda love (like) pada foto atau video yang diunggah. Populasi dalam penelitian ini adalah semua followers akun instagram Kopi Ramu. Karena jumlah followers yang terus bertambah, maka peneliti tidak dapat data yang valid mengenai jumlah populasi sehingga ukuran populasi penelitian ini dapat dikatakan tidak terhingga. Berdasarkan populasi yang tidak dapat diketahui secara pasti jumlahnya, maka dalam perhitungan jumlah ukuran sampel 
penelitian ini menggunakan rumus Cochran (Sugiyono, 2019):

$$
n=\frac{z^{2} p q}{\mathrm{e}^{2}}
$$

Keterangan:

$\mathrm{n}$ = Jumlah sampel yang dibutuhkan

$\mathrm{z}=$ Keterwakilan populasi dengan ditetapkan tingkat kepercayaan 95\% $(\alpha=0,05$ dengan $z=1,96)$

$\mathrm{p}=$ Peluang benar $50 \%=0,5$

$\mathrm{q}=$ Peluang salah $50 \%=0,5$

e $=$ Tingkat kesalahan maksimum 10\%

Teknik analisis data yang digunakan adalah analisis statistik deskriptif dan skor rata-rata. Pengujian validitas dan reliabilitas pada penelitian ini dilakukan dengan bantuan program IBM SPSS 26. Penelitian ini menggunakan model AISAS (Attention, Interest, Search, Action, Share) untuk mengukur efektivitas iklan produk Kopi Ramu pada media sosial instagram. Sedangkan untuk menganalisis perilaku pencarian informasi konsumen Kopi Ramu menggunakan model Sense Making Dervin. Setelah melakukan penilaian terhadap model AISAS dan pencarian informasi, selanjutnya diolah dengan mencari skor rata-rata menggunakan rumus sebagai berikut:

$$
x=\frac{\sum f_{i} \cdot w i}{\sum f_{i}}
$$

\section{Keterangan:}

$x \quad=$ Rata-rata berbobot

$f i \quad=$ Frekuensi

$w i=$ Bobot

Setelah itu, digunakan rentang skala penilaian untuk menentukan posisi tanggapan responden dengan menggunakan skor setiap variabel. Bobot alternatif yang terbentuk dari teknik skala peringkat terdiri atas kisaran antara 1 sampai 5 yang menggambarkan posisi dari sangat negatif ke posisi positif. Selanjutnya dilakukan perhitungan rentang skala dengan rumus sebagai berikut:

$$
R s=\frac{R(b o b o t)}{M}
$$

Keterangan:

$\mathrm{R}($ bobot $)=$ Bobot terbesar - terkecil

$\mathrm{M} \quad=$ Banyaknya kategori bobot

Rentang skala likert yang digunakan dalam penelitian ini adalah 1 sampai 5, maka rentang skala penilaian yang didapat adalah:

$$
R s=\frac{5-1}{5}=0,8
$$

Sehingga posisi keputusannya sebagaimana terlihat pada Tabel 1 . 
Tabel 1. Rentang Skala Keputusan Model AISAS

\begin{tabular}{|c|c|c|}
\hline No & Rentang Skala & Kriteria Keputusan \\
\hline 1 & $1,00<x \leq 1,80$ & $\begin{array}{l}\text { Sangat Tidak Efektif / } \\
\text { Sangat Negatif }\end{array}$ \\
\hline 2 & $1,80<x \leq 2,60$ & Tidak Efektif / Negatif \\
\hline 3 & $2,60<x \leq 3,40$ & $\begin{array}{c}\text { Cukup Efektif / Cukup } \\
\text { Positif }\end{array}$ \\
\hline 4 & $3,40<x \leq 4,20$ & Efektif / Positif \\
\hline 5 & $4,20<x \leq 5,00$ & $\begin{array}{c}\text { Sangat Efektif / Sangat } \\
\text { Positif }\end{array}$ \\
\hline
\end{tabular}

Sumber: Analisis Data Primer (2021)

Penggunaan kata efektif untuk mengukur efektifitas iklan sedangkan untuk pencarian informasi menggunakan kata positif.

\section{HASIL DAN PEMBAHASAN}

\section{Karakteristik Responden}

Tabel 2. Karakteristik Responden

\begin{tabular}{lcc}
\hline \multicolumn{1}{c}{ Deskripsi } & Jumlah & \% \\
\hline Jenis Kelamin & & \\
\hline a. Laki - Laki & 48 & 48 \\
b. Perempuan & 52 & 52 \\
\hline Usia & & \\
\hline a. <20 & 14 & 14 \\
b. 20-25 & 83 & 83 \\
c. 26-30 & 2 & 2 \\
d. > 30 & 1 & 1 \\
\hline Tingkat Pendidikan & & \\
\hline a. SD / Sederajat & 0 & 0 \\
b. SMP / Sederajat & 5 & 5 \\
c. SMA / Sederajat & 62 & 62 \\
d. Diploma & 10 & 10 \\
e. Sarjana & 21 & 21 \\
f. Pasca Sarjana & 2 & 2 \\
\hline Pekerjaan & & \\
\hline a. PNS & 0 & 0 \\
b. Pegawai Swasta & 10 & 10 \\
c. Wiraswasta & 5 & 5 \\
d. Pelaja/Mahasiswa & 75 & 75 \\
e. Lainnya & 10 & 10 \\
\hline Pendapatan per bulan & & \\
\hline a. < 1.000.000 & 52 & 52 \\
b. 1.000.000 - 2.000.000 & 21 & 21 \\
c. 2.000.001 - 3.000.000 & 11 & 11 \\
d. > 3.000.000 & 16 & 16 \\
\hline Sumber: Analisis Data Primer (2021) \\
\hline
\end{tabular}

Hasil penelitian menunjukkan bahwa followers Kopi Ramu tidak terbatas pada jenis kelamin tertentu. Hasil penelitian ini mendukung penelitian Sartika (2017) bahwa telah terjadi pergeseran budaya ngopi saat ini terlihat dari pengunjung kedai kopi tidak hanya dari kalangan laki-laki, tetapi kaum perempuan juga. Hal ini terjadi karena sekarang bukan hanya ada kopi hitam yang pahit, melainkan ada kopi susu, latte, mocca, dan cappuccino yang membuat banyak perempuan tertarik mengunjungi kedai kopi. Selain itu, perempuan juga dinilai lebih sering menjadikan kedai kopi sebagai tempat bertemu kerabat.

Tabel 2 menginformasikan bahwa followers followers instagram Kopi Ramu didominasi oleh pelajar/mahasiswa berusia 21-22 tahun. Hasil penelitian ini memiliki kesamaan dengan penelitian Fauziah (2018) bahwa konsumen Kedai Kopi di Kabupaten Banjarnegara didominasi oleh anak muda pada rentang usia 17 sampai 25 tahun sebanyak 84,6\%. Mayoritas followers instagram Kopi Ramu memiliki pendidikan terakhir berupa lulusan SMA atau sederajat yaitu sebesar $62 \%$, kemudian diikuti followers yang berpendidikan terakhir Sarjana sebesar 21\%, dan Diploma sebesar 10\%. 
Hal tersebut menunjukkan bahwa followers instagram Kopi Ramu sangat memahami akan pentingnya pendidikan. Menurut Sumarwan (2011), tingkat pendidikan seseorang akan mempengaruhi proses pembelian dan pola konsumsinya. Semakin tinggi tingkat pendidikan, seseorang akan semakin responsif dalam menerima informasi dan mempengaruhi konsumen tersebut dalam proses pengambilan keputusan pembelian.

Hasil penelitian menunjukkan bahwa mayoritas followers instagram Kopi Ramu memiliki pendapatan di bawah Rp1.000.000 dengan persentase sebesar 52\%, diikuti dengan followers yang berpendapatan antara Rp1.000.000 sampai Rp2.000.000 sebesar 21\%. Kecilnya jumlah pendapatan dalam satu bulan followers instagram kopiramu disebabkan karena sebagian besar followers adalah pelajar atau mahasiswa, dimana sumber pendapatan tersebut diterima dari orang tua. Hasil penelitian ini memiliki kesamaan dengan penelitian Deas (2019) bahwa rata-rata pendapatan konsumen Kedai Utama EL'S Coffee di Kota Bandar Lampung didominasi oleh konsumen yang berpendapatan Rp500.001 sampai Rp1.500.000 dengan persentase sebesar $47 \%$.

\section{Analisis Attention (Perhatian) Terhadap Iklan}

Tabel 3. Skor Variabel Attention

\begin{tabular}{|c|c|c|c|}
\hline No & Variabel Attention & Skor & Keterangan \\
\hline 1 & $\begin{array}{l}\text { Iklan menarik } \\
\text { perhatian audiens }\end{array}$ & 4,18 & Efektif \\
\hline 2 & $\begin{array}{l}\text { Mengetahui } \\
\text { berbagai produk } \\
\text { kopi ramu }\end{array}$ & 4,24 & $\begin{array}{l}\text { Sangat } \\
\text { Efektif }\end{array}$ \\
\hline 3 & $\begin{array}{l}\text { Mengingat varian } \\
\text { produk kopi ramu }\end{array}$ & 4,16 & Efektif \\
\hline \multicolumn{2}{|c|}{ Rata-rata } & 4,19 & Efektif \\
\hline
\end{tabular}

Sumber: Analisis Data Primer (2021)

Berdasarkan hasil penyebaran kuesioner didapatkan bahwa nilai attention (perhatian) adalah sebesar 4,19. Nilai ini berada pada rentang skala 3,40 4,19 yaitu "Efektif". Maka dapat disimpulkan bahwa iklan produk Kopi Ramu pada media sosial instagram adalah efektif membuat followers menaruh perhatian kepada iklan produk Kopi Ramu yang muncul pada media sosial instagram. Hal ini ditandai oleh sebagian besar responden dapat mengetahui dan mengingat produk yang dijual oleh Kopi Ramu sebelum menuju ke tahapan-tahapan selanjutnya.

\section{Analisis Interest (Ketertarikan) Terhadap Iklan}

Tabel 4. Skor Variabel Interest

\begin{tabular}{clcc}
\hline No & Variabel Interest & Skor & Keterangan \\
\hline 1 & $\begin{array}{l}\text { Frekuensi } \\
\text { unggahan iklan }\end{array}$ & 4,04 & Efektif \\
2 & $\begin{array}{l}\text { Caption iklan } \\
\text { yang menarik }\end{array}$ & 3,86 & Efektif \\
3 & $\begin{array}{l}\text { Desain cup yang } \\
\text { kekinian }\end{array}$ & 4,18 & Efektif \\
4 & $\begin{array}{l}\text { Banyaknya varian } \\
\text { rasa }\end{array}$ & 4,22 & $\begin{array}{l}\text { Sangat } \\
\text { Efektif }\end{array}$ \\
\hline Rata-rata & 4,07 & Efektif \\
\hline Sumber: Analisis Data Primer $(2021)$ &
\end{tabular}


Berdasarkan hasil penyebaran kuesioner didapatkan bahwa nilai interest (ketertarikan) adalah sebesar 4,07. Nilai ini berada pada rentang skala 3,40 - 4,19 yaitu "Efektif". Maka dapat disimpulkan bahwa iklan produk Kopi Ramu pada media sosial instagram efektif membuat followers menjadi tertarik pada produk yang ditawarkan. Hal ini berhubungan dengan seringnya Kopi Ramu mengunggah konten di instagram dengan caption yang lebih personal sehingga masuk ke dalam benak followers yang lama kelamaan membuat followers menjadi terarik untuk mengonsumsi produk Kopi Ramu, serta desain cup yang dianggap related dengan anak muda menjadi daya tarik tersendiri bagi para calon konsumen. Selain itu, banyaknya varian rasa yang ditawarkan ternyata menimbulkan ketertarikan followers untuk mengonsumsi produk Kopi Ramu karena nantinya konsumen akan lebih leluasa untuk memilih varian rasa yang paling mereka sukai.

\section{Analisis Search (Mencari Informasi) Terhadap Iklan}

Tabel 5. Skor Variabel Search

\begin{tabular}{|c|c|c|c|}
\hline No & Variabel Search & Skor & Keterangan \\
\hline 1 & $\begin{array}{l}\text { Mencari informasi } \\
\text { harga produk }\end{array}$ & 3,95 & Efektif \\
\hline 2 & $\begin{array}{l}\text { Mencari informasi } \\
\text { kualitas produk }\end{array}$ & 4,17 & Efektif \\
\hline 3 & $\begin{array}{l}\text { Mencari informasi } \\
\text { lokasi Kedai Kopi } \\
\text { Ramu }\end{array}$ & 4,13 & Efektif \\
\hline
\end{tabular}

Sumber: Analisis Data Primer (2021)

Berdasarkan hasil penyebaran kuesioner didapatkan bahwa nilai search (mencari informasi) adalah sebesar 4,08. Nilai ini berada pada rentang skala 3,40 4,19 yaitu "Efektif". Maka dapat disimpulkan bahwa iklan produk Kopi Ramu pada media sosial instagram efektif membuat followers melakukan pencarian lebih lanjut mengenai produk yang ditawarkan. Hasil penelitian ini mendukung hasil penelitian Esperanza, Fatimah, dan Kusno (2016) yang menyatakan bahwa informasi yang dicari konsumen melalui media sosial mengenai restoran biasanya adalah mengenai variasi menu, harga, pelayanan, dan informasi lain mengenai pemesanan. Tahap search adalah tahap dimana seseorang sudah mulai mencari tahu mengenai informasi produk yang diiklankan. Tahapan ini mendapatkan hasil 4,08 yang berarti efektif sehingga iklan produk Kopi Ramu di media sosial instagram sudah bisa menumbuhkan 
keinginan audiens untuk melakukan tindakan ke tahap selanjutnya yakni tahap action.

\section{Analisis Action (Tindakan) Terhadap Iklan}

Tabel 6. Skor Variabel Action

\begin{tabular}{clcc}
\hline No & $\begin{array}{c}\text { Variabel } \\
\text { Action }\end{array}$ & Skor & Keterangan \\
\hline 1 & $\begin{array}{l}\text { Iklan yang } \\
\text { sesuai dengan } \\
\text { produk }\end{array}$ & 4,05 & Efektif \\
2 & $\begin{array}{l}\text { Kalimat kreatif } \\
\text { dalam iklan } \\
\text { Promosi dalam } \\
\text { iklan }\end{array}$ & 3,98 & Efektif \\
\hline Rata-rata & 4,02 & Efektif \\
\hline
\end{tabular}

Sumber: Analisis Data Primer (2021)

Berdasarkan hasil penyebaran kuesioner didapatkan bahwa nilai action (tindakan) adalah sebesar 4,02. Nilai ini berada pada rentang skala 3,40 - 4,19 yaitu "Efektif". Maka dapat disimpulkan bahwa iklan produk Kopi Ramu pada media sosial instagram efektif membuat followers melakukan tindakan untuk membeli produk yang ditawarkan. Iklan belum mempertunjukkan bagiannya sampai mereka telah mencapai tujuan mereka yaitu mendorong target audiens untuk melakukan tindakan atau action.

\section{Analisis Share (Membagikan Informasi) Terhadap Iklan}

Tabel 7. Skor Variabel Share

\begin{tabular}{cccc}
\hline No & \multicolumn{1}{c}{$\begin{array}{c}\text { Variabel } \\
\text { Share }\end{array}$} & Skor & Keterangan \\
\hline 1 & $\begin{array}{l}\text { Membagikan cerita } \\
\text { setelah merasakan } \\
\text { produk }\end{array}$ & & Efektif \\
2 & $\begin{array}{l}\text { Membagikan cerita } \\
\text { setelah tahu suasana } \\
\text { lokasi Kedai Kopi }\end{array}$ & & Efektif \\
& $\begin{array}{l}\text { Ramu } \\
\text { Melakukan update }\end{array}$ & 3,66 & Efektif \\
& $\begin{array}{l}\text { status di media } \\
\text { sosial }\end{array}$ & & \\
\hline Rata-rata & & 3,89 & Efektif \\
\hline Sumber:Analisis Data Primer $(2021)$ &
\end{tabular}

Sumber: Analisis Data Primer (2021)

Berdasarkan hasil penyebaran kuesioner didapatkan bahwa Dari perhitungan tersebut, nilai share (membagikan informasi) adalah sebesar 3,89. Nilai ini berada pada rentang skala 3,40 - 4,19 yaitu "Efektif". Maka dapat disimpulkan bahwa iklan produk Kopi Ramu pada media sosial instagram efektif membuat followers membagikan informasi pengalamannya dalam membeli produk Kopi Ramu. Iklan pada media sosial instagram mendorong konsumen untuk membagikan informasi dengan berbicara pada orang lain mengenai produk yang diiklankan atau memberi komentar di internet.

\section{Skor Rata-rRata Efektivitas Iklan}

Setelah masing-masing variabel AISAS (Attention, Interest, Search, Action, Share) diketahui jumlah rataratanya, selanjutnya yaitu dilakukan 
perhitungan berdasarkan keseluruhan AISAS untuk mengetahui jumlah ratarata akhir. Perhitungan ini diolah dengan menggunakan pendekatan rumus skor rata-rata yang kemudian didapatkan hasil sebagai berikut:

Tabel 8. Skor Rata - Rata Efektivitas Iklan

\begin{tabular}{clcc}
\hline No & Model AISAS & Skor & Keterangan \\
\hline 1 & Attention & 4,19 & Efektif \\
2 & Interest & 4,07 & Efektif \\
3 & Search & 4,08 & Efektif \\
4 & Action & 4,02 & Efektif \\
5 & Share & 3,89 & Efektif \\
\hline \multicolumn{2}{l}{ Skor Rata - Rata } & 4,05 & Efektif \\
\hline
\end{tabular}

Sumber: Analisis Data Primer (2021)

Berdasarkan data hasil perhitungan skor rata-rata AISAS pada tabel di atas, diketahui bahwa skor pemberian bobot yang dimiliki oleh masing-masing tahapan AISAS yang diperoleh dari 100 jawaban responden yaitu tahap attention mendapatkan skor rata-rata sebesar 4,19, tahap interest 4,07, tahap search 4,08, tahap action 4,03, tahap share 3,89 dan didapatkan skor rata-rata keseluruhan AISAS sebesar 4,05. Hasil keseluruhan AISAS berada pada rentang skala 3,40 4,19 yaitu "Efektif".

Dari hasil yang telah diperoleh, dapat disimpulkan bahwa iklan Kopi Ramu pada media sosial instagram efektif dalam menarik perhatian dan meyakinkan audiens untuk melakukan tindakan mengonsumsi produk Kopi Ramu khususnya pada followers media sosial instagram Kopi Ramu. Hasil penelitian ini mendukung hasil penelitian Juliaristanti, Ramdan dan Jhoansyah (2020) yang menyatakan bahwa iklan produk kosmetik wardah yang ditampilkan pada instagram stories advertisement terbilang cukup efektif, serta mampu menarik perhatian dan meyakinkan audiens. Hasil data yang diperoleh sudah sesuai dengan kriteria AISAS yang menjelaskan bahwa tahapan attention merupakan tahapan yang mengukur seberapa besar iklan dapat menarik perhatian konsumen terhadap produk yang ditawarkan dan sejauh mana konsumen akan sadar terhadap produk tersebut. Interest yaitu tahapan yang mengukur seberapa besar iklan dapat membuat konsumen tertarik untuk mengonsumsi produk yang ditawarkan. Search yaitu tahapan yang mengukur seberapa besar iklan dapat membuat konsumen melakukan pencarian lebih lanjut mengenai hal yang berhubungan dengan produk yang ditawarkan. Action yaitu tahapan yang mengukur seberapa besar iklan dapat membuat konsumen mengambil tindakan untuk melakukan pembelian terhadap produk yang ditawarkan. Tahap terakhir yaitu share yang merupakan tahap yang mengukur seberapa besar iklan dapat membuat konsumen membagikan informasi atas 
pengalaman yang mereka dapatkan setelah membeli produk yang ditawarkan.

\section{Analisis Data Pencarian Informasi}

Ngopi bagi sebagian orang bukan hanya sekedar minum kopi tetapi sudah menjadi gaya hidup. Kedai kopi seringkali dijadikan opsi untuk melakukan interaksi oleh masyarakat. Pergi ke Kedai Kopi menjadi ajang sosialisasi dan sebagai media pencarian informasi. Hal ini deperkuat dengan hasil survei kepada 100 responden followers media sosial instagram Kopi Ramu bahwa mereka datang ke Kedai Kopi bukan hanya untuk menikmati kopi, tetapi juga sebagai sarana untuk memperoleh informasi. Hasil penelitian menunjukkan bahwa hanya sedikit orang yang ke Kedai Kopi Ramu hanya untuk minum kopi yaitu 16 orang atau dalam persentase $16 \%$. Sebagian besar followers media sosial instagram Kopi Ramu ingin mencari informasi dengan mengunjungi Kedai Kopi Ramu yaitu sebanyak 84 orang atau dalam persentase $84 \%$. Jenis informasi yang dicari rata-rata mengenai suatu topik yaitu sebanyak 47 orang atau dalam persentase $47 \%$, diikuti oleh mengerjakan tugas/skripsi sebanyak 33 orang atau dalam persentase $33 \%$, mencari informasi tentang kopi sebanyak
9 orang atau dalam persentase $9 \%$, rapat pekerjaan sebanyak 7 orang atau dalam persentase $7 \%$, dan hanya sedikit yang datang untuk sekedar nongkrong yaitu sebanyak 4 orang atau dalam persentase $4 \%$.

\section{Skor Rata-rata Pencarian Informasi}

Tabel 9. Skor Rata-rata Pencarian Informasi

\begin{tabular}{|c|c|c|c|}
\hline No & Pernyataan & Skor & Keterangan \\
\hline 1 & $\begin{array}{l}\text { Mencari informasi } \\
\text { di Kedai Kopi } \\
\text { Ramu }\end{array}$ & 3,86 & Positif \\
\hline 2 & $\begin{array}{l}\text { Sharing informasi di } \\
\text { Kedai Kopi Ramu }\end{array}$ & 4,35 & $\begin{array}{l}\text { Sangat } \\
\text { Positif }\end{array}$ \\
\hline 3 & $\begin{array}{l}\text { Informasi yang } \\
\text { sesuai dengan } \\
\text { kebutuhan }\end{array}$ & 3,84 & Positif \\
\hline 4 & $\begin{array}{l}\text { Sumber informasi } \\
\text { yang paling } \\
\text { dipercaya }\end{array}$ & 3,55 & Positif \\
\hline 5 & $\begin{array}{l}\text { Mencari informasi } \\
\text { tentang } \\
\text { membedakan rasa, } \\
\text { aroma, warna kopi } \\
\text { asli }\end{array}$ & 3,42 & Positif \\
\hline 6 & $\begin{array}{l}\text { Skill meracik kopi } \\
\text { di rumah meningkat }\end{array}$ & 2,96 & $\begin{array}{l}\text { Cukup } \\
\text { Positif }\end{array}$ \\
\hline 7 & $\begin{array}{l}\text { Kemampuan untuk } \\
\text { menggunakan } \\
\text { perpustakaan }\end{array}$ & 3,65 & Positif \\
\hline 8 & $\begin{array}{l}\text { Menggunakan } \\
\text { informasi sebagai } \\
\text { solusi dalam } \\
\text { menghadapi } \\
\text { masalah }\end{array}$ & 4,1 & Positif \\
\hline 9 & $\begin{array}{l}\text { Semua informasi } \\
\text { yang didapatkan di } \\
\text { Kedai Kopi Ramu } \\
\text { digunakan untuk } \\
\text { mengatasi masalah }\end{array}$ & 3,26 & $\begin{array}{l}\text { Cukup } \\
\text { Positif }\end{array}$ \\
\hline 10 & $\begin{array}{l}\text { Individu yang aktif } \\
\text { setiap hari mencari } \\
\text { informasi baru }\end{array}$ & 3,98 & Positif \\
\hline Sko & Rata - Rata & 3,697 & Positif \\
\hline
\end{tabular}

Sumber: Analisis Data Primer (2021)

Berdasarkan data hasil perhitungan skor rata-rata pada tabel di atas, didapatkan skor rata-rata keseluruhan pencarian informasi sebesar 3,697. Skor 
ini berada pada rentang skala $3,40-4,19$ yang menunjukkan bahwa perilaku pencarian informasi followers media sosial instagram Kopi Ramu itu "Positif".

Dapat disimpulkan bahwa Kedai Kopi Ramu mengalami pergeseran fungsi. Konsumen datang ke Kedai Kopi Ramu bukan hanya untuk minum kopi semata, tetapi juga untuk mencari informasi. Ketika seseorang sedang mengalami masalah dan perlu mencari informasi, banyak yang memilih pergi ke café untuk menyelesaikan masalahnya. Sekarang Kedai Kopi menjadi tempat mencari informasi penting, diskusi, bersosialiasi, serta mencari hiburan. Hasil penelitian ini mendukung hasil penelitian Yuliani (2019) yang menyatakan bahwa keberadaan warung kopi di Banda Aceh saat ini cenderung menggantikan kedudukan perpustakaan sebagai tempat pencarian informasi. Fasilitas yang ditawarkan oleh warung kopi seperti wifi, ruang sholat, ruang diskusi, sofa, tv, kipas angin, infocus, ruangan tertutup dan terbuka yang ada di Banda Aceh menjadi salah satu penyebab mahasiswa cenderung ke warung kopi dari pada ke perpustakaan. Penelitian Firsyawardana dan Rahmanto (2019) juga menyatakan bahwa adanya motif pencarian informasi dalam mengunjungi Kedai Kopi. Dengan mengunjungi Kedai Kopi Bertopi, informan ingin mengetahui tentang bagaimana sajian kopi yang ditawarkan oleh Kedai Kopi ini. Selain itu, informan juga memanfaatkan kehadiran orang yang dikenal untuk memberikan informasi mengenai komposisi dari sajian-sajian kopi yang dihadirkan di Kedai Kopi Bertopi. Berdasarkan hasil penelitian Sartika (2017), ngopi tidak hanya sekedar minum kopi tetapi juga sebagai gaya hidup. Ngopi menjadi salah satu ajang bersosialisasi dan memperoleh informasi.

\section{KESIMPULAN DAN SARAN Kesimpulan}

Berdasarkan hasil penelitian dan analisis yang telah dilakukan dapat ditarik kesimpulan sebagai berikut:

1. Karakteristik followers instagram Kopi Ramu didominasi oleh pelajar/ mahasiswa berusia 20-25 tahun, tidak terbatas pada jenis kelamin tertentu, serta berpendidikan terakhir berupa lulusan SMA atau sederajat dengan pendapatan atau uang saku di bawah Rp1.000.000.

2. Iklan Kopi Ramu yang ditampilkan pada media sosial instagram berada pada kategori “Efektif”. Hal ini dapat dilihat dari hasil skor rata-rata yang 
didapatkan yaitu sebesar yaitu sebesar 4,05. Variabel attention memiliki nilai efektivitas sebesar 4,19 dalam kategori "Efektif", interest sebesar 4,07 dalam kategori "Efektif", search sebesar 4,08 dalam kategori "Efektif", action sebesar 4,02 dalam kategori "Efektif", dan share sebesar 3,89 dalam kategori "Efektif".'

3. Perilaku pencarian informasi di Kedai Kopi Ramu adalah "Positif". Hal ini dapat dilihat dari hasil skor rata-rata yang didapatkan yaitu sebesar 3,697.

\section{Saran}

Berdasarkan hasil penelitian yang diperoleh, adapun saran yang dapat diajukan oleh penulis adalah sebagai berikut:

1. Jika membandingkan hasil nilai dari kelima variabel, maka variabel yang memiliki nilai terbawah adalah action dan share. Agar efektivitas iklan ini maksimal, maka perlu adanya kinerja serta evaluasi yang berkaitan dengan variabel action dan share. Untuk meningkatkan action, Kopi Ramu dapat lebih memperkaya konten di feeds instagram seperti suasana Kedai Kopi Ramu, fasilitas yang tersedia, dan promo menarik untuk mahasiswa. Kopi Ramu juga dapat mempercantik desain interior maupun eksterior dan meningkatkan kualitas produk supaya konsumen dapat membagikan informasi (share) yang secara tidak langsung akan membantu pihak marketing dalam menarik lebih banyak konsumen.

2. Packaging Kopi Ramu yang masih berbahan dasar plastik sebaiknya diganti menggunakan bahan yang lebih ramah lingkungan. Kopi Ramu dapat mempertimbangkan berbagai alternatif seperti bahan kertas, rumput laut atau jelly, atau PLA (Polyatic Acid) yang sangat mirip dengan plastik namun biodegradable dan compostable. Kopi Ramu juga dapat membuat promosi jika konsumen datang membawa tumbler diberikan penawaran spesialSebagian besar responden menjadikan Kedai Kopi Ramu sebagai media pencarian informasi, maka dari itu perlu adanya fasilitas-fasilitas yang menunjang konsumen untuk mencari informasi. Fasilitas yang perlu disediakan Kedai Kopi Ramu yaitu ruangan indoor yang lebih nyaman, perbanyak stop kontak, menyediakan ruang baca, dan ruangan yang bisa dipakai untuk rapat. 


\section{DAFTAR PUSTAKA}

Bestriandita, D. and Widodo, E. (2017) 'Analisis Perbandingan Efektivitas Iklan Menggunakan EPIC Model Terhadap Mahasiswa UII Yogyakarta', Prosiding Seminar Nasional Integrasi Matematika dan Nilai Islami, 1(1), pp. 214-220.

Cresswell, J. W. (2016) Research Design: Pendekatan Kualitatif, Kuantitatif, dan Mixed. Yogyakarta: Pustaka Belajar.

Deas, R. Q. P. (2019) Analisis Kepuasan Konsumen Kedai Utama El's Coffee Kota Bandar Lampung. Institut Pertanian Bogor.

Esperanza, D., Fatimah, S., \& Kusno, R. A. (2016). Analisis Komunikasi Pemasaran Berbasis Media Sosial di Kalangan Restoran Elit dan Menengah di Kota Bandung. Agricore: Jurnal Agribisnis dan Sosial Ekonomi Pertanian Unpad, 1(2).

Echsanullah, M. and Wulandari, A. (2018) 'Pameran, Personal Selling Dan Iklan Media Online Dalam Mendorong Penjualan Property', Jurnal Pengembangan Wiraswasta, 20(3), p. 171. doi: 10.33370/jpw.v20i3.266.

Fauzi, A. R. (2020) Fenomena ngopi sebagai gaya hidup di kalangan generasi millenial: perubahan perilaku dan perubahan sosial masyarakat di Kecamatan Pengalengan Kabupaten Bandung. UIN Sunan Gunung Djati.

Fauziah, S. N. (2018) Analisis Segmentasi Konsumen Kedai Kopi di Kabupaten Banjarnegara, Jawa Tengah. Institut Pertanian Bogor.

Firsyawardana, M. R. and Rahmanto, A. N. (2019) 'Motif Pengunjung dan Perilaku Komunikasi di Kedai Kopi', Jurnal komunikasi massa, 1.

Juliaristanti, V., Ramdan, A. M. and Jhoansyah, D. (2020) 'Analisis
Karakteristik Followers dan Konten Iklan Dalam Mengukur Efektivitas Instagram Stories Advertisement Pada Produk Kosmetik Wardah', Syntax Idea, 2(8), pp. 503-513. Available at: https://jurnal.syntaxidea.co.id/index.php/syntaxidea/article/view/502/411.

Prakosa, A. (2019) 'Generasi Third Wave Coffee: Perspektif Milenial Terhadap Kopi Gelombang Ketiga', Bisman (Bisnis dan Manajemen): The Journal of Business and Management, 2(2), pp. 106-118.

Sartika, R. (2017) 'Pergeseran Budaya Ngopi Di Kalangan Generasi Muda Di Kota Tanjungpinang', Jurnal Umrah. Available at: http://jurnal.umrah.ac.id/wpcontent/uploads/gravity_forms/1ec61c9cb232a03a96d0947c6478e5 25e/2017/02/JURNAL35.pdf.

Solikatun, S., Kartono, D. T. and Demartoto, A. (2015) 'Perilaku Konsumsi Kopi Sebagai Budaya Masyarakat Konsumsi (Studi Fenomenologi Pada Peminum Kopi Di Kedai Kopi Kota Semarang), Jurnal Analisa Sosiologi, 4(1), pp. 60-74.

Sugiyama, K. and Andree, T. (2011) The Dentsu Way: Secrets of Cross Switch Marketing from The World's. McGraw Hill.

Sugiyono (2019) Metode Penelitian Kuantitatif, Kualitatif, dan R\&D. Bandung: CV. Alfabeta.

Sumarwan, U. (2011) Perilaku Konsumen Teori dan Penerapannya dalam Pemasaran. 2nd edn. Bogor (ID): PT Ghalia Indonesia.

We Are Social and Hootsuite. (2021) 'Digital 2020 Indonesia: All The Data, Trends, and Insights You Need to Help You Understand How People Use the Internet, Mobile, Social Media, and Ecommerce', 
Jurnal Pemikiran Masyarakat Ilmiah Berwawasan Agribisnis. Juli 2021. 7(2): 1254-1270

Diakses pada tanggal 20 Juni 2020

tal-2021-indonesia.

dari

https://datareportal.com/reports/digi 